\title{
A systematic review of penile prosthesis infection and meta-analysis of diabetes mellitus role
}

\author{
Lucas Mira Gon* ${ }^{*}$, Caio César Citatini de Campos, Brunno Raphael lamashita Voris, Luís Augusto Passeri, \\ Adriano Fregonesi and Cássio Luís Zanettini Riccetto
}

\begin{abstract}
Background: Infection is the most feared complication of a penile prosthesis. Diabetes mellitus (DM) is widely known to increase the risk of several infections, but its role in the penile prosthesis is still controversial. This systematic review aims to show the contemporary scenario of penile prosthesis infection and present a meta-analysis about DM contribution to penile prosthesis infection.

Methods: The review was performed with no language or time limitation, including ten databases. The included articles were about the male population who received a penile prosthesis with no model restriction, with a minimum follow up of 1 year, and outcomes adequately reported.

Results: The mean infection incidence of penile prosthesis ranged from 0.33 to $11.4 \%$. In early 2000, the general incidence of infection was 3 to $5 \%$, then, the introduction of coated materials decreased it to 0.3 to $2.7 \%$. The metaanalysis showed that diabetes mellitus is related to an increased risk of penile prosthesis infection with an odds ratio of $1.53(95 \% \mathrm{Cl} 1.15-2.04)$.

Conclusions: Penile prosthesis infection decreased in the last decades but remains a significant cause of reoperation, and it is related to lower prosthesis survival. Meta-analysis concludes that diabetes mellitus is related to a higher risk of penile prosthesis infection.
\end{abstract}

Keywords: Penile prosthesis, Penile implants, Infection, Review, Meta-analysis, Diabetes mellitus

\section{Background}

The penile prosthesis was introduced in the 1970s and remained the most effective treatment to erectile dysfunction refractory to oral and injectable drugs $[1,2]$. In the last 40 years, several improvements in materials and surgical techniques led to high satisfaction rates of 80 to $90 \%[3,4]$. However, complications do exist and range from 7 to $20 \%$ [5], mostly related to mechanical malfunction, infection, and erosion. The estimated cost of penile

\footnotetext{
*Correspondence: lucasmgon@gmail.com
}

Division of Urology of Department of Surgery, Faculty of Medical

Sciences, Hospital de Clinicas, University of Campinas - UNICAMP, Rua

Vital Brazil, 250, Campinas, SP 13083-590, Brazil prosthesis removal is about 10 thousand dollars, which is six-fold higher than the initial implantation [6].

Surgical site infection is the most feared complication. It causes pain, local abscess, and even sepsis that requires prompt hospitalization and reoperation [7]. The prosthesis removal leads to fibrosis of the cavernosum corpus and reduction of penile length and girth, making a new prosthesis insertion much more difficult [8].

Diabetes mellitus (DM) impairs microcirculation and causes neuropathy, and approximately $50 \%$ of diabetic patients have some degree of erectile dysfunction. The corpus cavernosum of diabetic patients are less responsive to relaxation due to the superoxide radicals production, impairing nitrous oxide and cyclic-GMP 
production. Thus, diabetic patients are less responsive to oral therapy [9]. Patients with diabetes are more prone to infection because of leucocyte dysfunction and microangiopathy. There is evidence of a three-fold higher risk of penile prosthesis infection in DM compared to nondiabetic patients. However, other studies show no difference, and there is still controversy about whether DM increases the risk of penile prosthesis infection $[10,11]$.

Several device improvements reduced mechanical failures of penile prosthesis, but infection remained an important cause of reoperation. Therefore, the efforts were directed to reduce infection in the past years $[8$, 12]. This study aims to gather information about penile prosthesis evolution regarding infections and to present a meta-analysis of diabetes mellitus contribution to penile prosthesis infection.

\section{Methods}

This review was performed with no language or time limitation, to gather all available data about penile prosthesis, in ten databases: Medline, PubMed, LILACS, IBECS, MEdCarib, CINAHL, Scopus, Web of Science, Embase and Cochrane Library. The search strategy included the terms: "penile prosthesis" or "penile implantation" and "postoperative complications" or "prosthesis-related infections" or "treatment outcome". It followed the PRISMA statement, was registered at PROSPERO with number CRD 42019117734, and had no founding resources.

All the articles had the title and abstract evaluated by two independent authors who selected relevant studies blinded from each other. A third and more experienced author resolved conflicting selection. The included articles were about the male population who received a penile prosthesis with no model restriction, with a minimum follow up of 1 year, outcomes and complications adequately reported. The studies had quality assessed using "Grading of Recommendations, Assessment, Development and Evaluations" (GRADE) framework [13]. The evaluated outcomes were surgical site infection, prosthesis infection, prosthesis revision, and removal. The outcomes were compared with time, techniques, prosthesis types, and diabetes mellitus presence.

The exclusion criteria were case reports, articles about surgical technique, and in vitro tests. All studies about transgender patients were excluded, as they assess a specific population and different surgical procedures. The studies focused on the quality of life without outcomes assessment, and those that stated to have no complications were excluded either. Considering infection incidence, studies that started with less than a hundred patients were excluded due to the risk of underestimation of complications.
Each study had data extracted including author, publication year, study design, penile prosthesis type, the number of patients, mean age, follow-up, infection, reoperation, prosthesis removal, or replacement. The data are presented as incidence ratio, with mean and standard deviation when available. The relation between diabetes mellitus and penile prosthesis infection is presented with a meta-analysis, and odds ratio calculated with Open Meta for Macintosh version 12.11.14. Significance was adopted as $p<0.05$ and $95 \%$ confidence interval (95\% CI).

\section{Results}

\section{Literature overview}

The research strategy was completed in January 2018 and turned out 4164 articles. After excluding 2012 duplicates, the 2152 articles had titles analyzed by two authors, who excluded yet 464 duplicates. The remaining had the abstract analyzed to exclude case reports, experimental studies, retrospective, and small series. In the end, 80 articles were fully assessed for eligibility, and 41 included in the analysis. The study selection is shown in a flow diagram (Fig. 1), while Table 1 presents the characteristics of the included studies and the infection rates.

The literature about penile prosthesis relies on prospective cohorts, retrospective studies, and case series; the majority of studies do not present controls, or use historical data as controls. There is only one randomized trial available about the AMS 700 (American Medical Systems, Minneapolis, MN, USA) and the Titan (Coloplast, Minneapolis, MN, USA), presented in 2013 [14]. Both are inflatable and coated penile prosthesis, and were evaluated for satisfaction, curvature correction for Peyronie's disease and mechanical survival. There were only 2 cases of infection from 138 patients with no report of group or time. The authors state that there was no statistical difference between groups, and the study was not designed to assess infection. Table 1 shows all the included studies with the infection incidence in each one.

\section{Diabetes mellitus and penile prosthesis infections}

Diabetes mellitus is a well-established risk factor for several infections; however, the relation with penile prosthesis infection is still controversial. Diabetic patients are more susceptible to infections because of impaired defense mechanisms, including leukocyte dysfunction and impaired mobilization to the infection site due to angiopathy [10].

We summarized the available evidence about penile prosthesis infection and DM in a meta-analysis, including 9041 diabetic patients and 36,517 non-diabetics. The meta-analysis shows that DM increases the incidence of penile prosthesis infection with an odds ratio of 1.53 (95\% CI 1.15-2.04; $p=0.004)$, as shown in Fig. 2. 


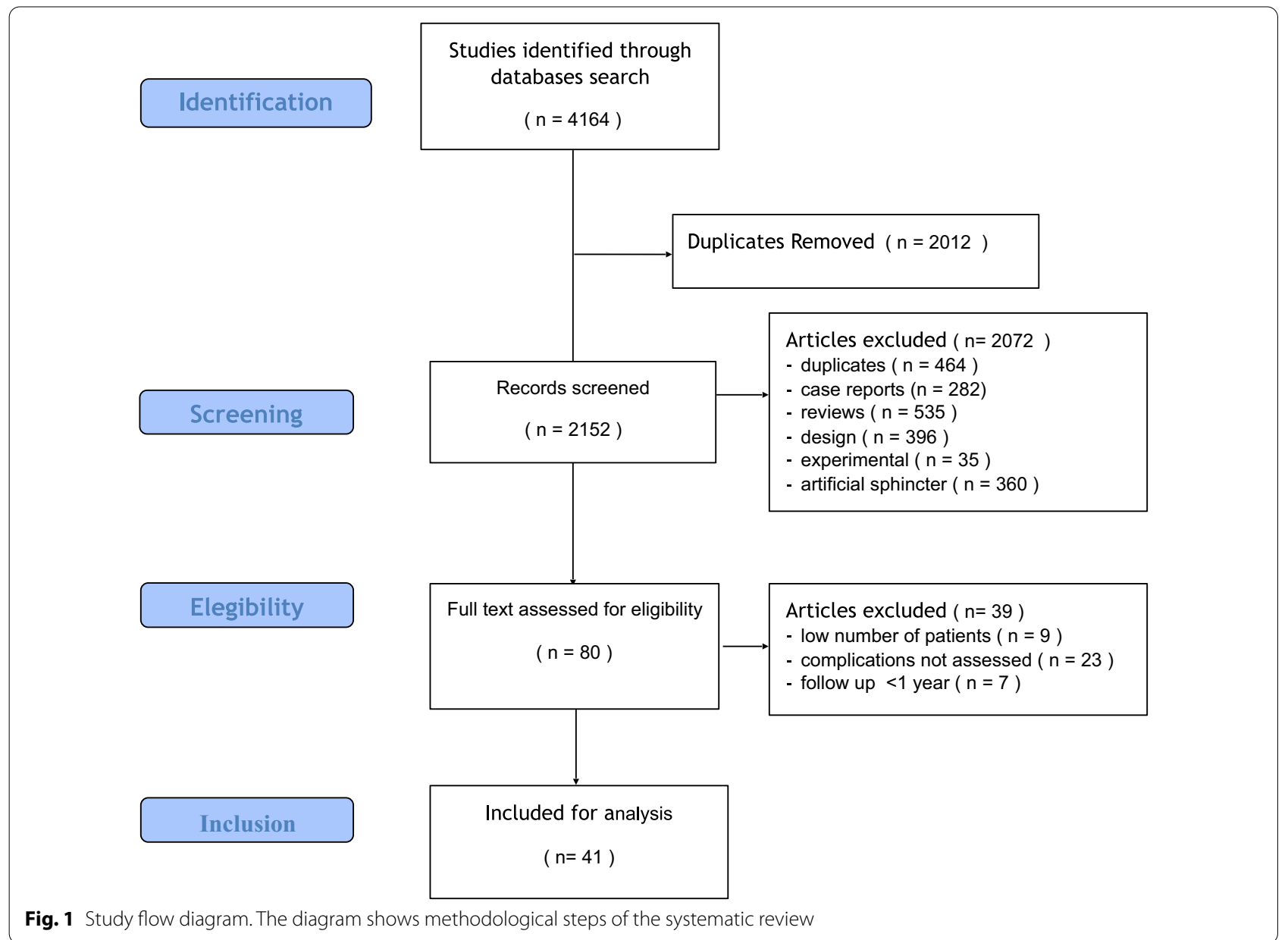

Fallon and Ghanen reported a three-fold higher risk of infection in diabetic patients, while Bishop et al. [15] suggested glycosylated hemoglobin as an infection predictor in the early 1990s. On the other hand, Wilson and Delk [16] found no relation between diabetes mellitus and infection in a retrospective study with 823 patients. However, three years later, the same authors presented a prospective study with 114 diabetic patients and 275 non-diabetics and found a trend toward more infection in the diabetic group $(8.8 \%$ vs. $4 \% ; p=0.06)$ [10]. Mulcahy and Carson [11], in a review of the manufacturer's database, including 31,341 men using a coated penile prosthesis, reported that the general revision rate was significantly higher in patients with diabetes: $1.72 \%$ versus $1.26 \%(p=0.005)$.

\section{Decreasing infection strategies}

The mean incidence of penile prosthesis infection decreased over time. Around the 1980s and 1990s, the incidence was about 8 to $11 \%$, and in early 2000 it was 3 to $5 \%$. The introduction of the coated prosthesis and technique improvements decreased the infection incidence to a current rate of about 0.3 to $2.7 \%$. The incidence of infection in the included studies is shown in Table 1.

In 2000, the American Medical Systems (AMS) introduced a prosthesis coated with the InhibiZone ${ }^{\mathrm{TM}}$, which consists of an antibiotic coating using minocycline and rifampicin that elutes in tissues around the device and inhibit the bacterial growth. In 2004, Carson described results from the manufacturer's database, showing $0.28 \%$ rate of infection in prosthesis with InhibiZone ${ }^{\mathrm{TM}}$, while regular uncoated ones had $1.59 \%$ at 60 days after surgery ( $p$ 0.003). At 6 months, the incidence was $0.68 \%$ in the coated group and $1.61 \%$ in the control one ( $p$ 0.005) [17].

In 2002 Mentor (now Coloplast) introduced the Titan, which has a hydrophilic coating that reduces bacterial adherence and can diffuse antibiotics when immersed into an antibiotic solution during surgery [18]. In 2004, Wolter and Hellstrom published data about infection from Mentor's database and FDA explantation reports. At 1 year follow-up, the infection rate in Titan prosthesis 
Table 1 Included articles. The list of studies included as results of the systematic review, and infection rates

\begin{tabular}{|c|c|c|c|c|c|c|c|c|c|}
\hline & Study & Year & Design & $\begin{array}{l}\text { Level } \\
\text { of evidence } \\
\text { grade }\end{array}$ & Period & Prosthesis type & Patient $n$ & Infection $n$ & Infectionrate (\%) \\
\hline 1 & Carson et al. [34] & 1983 & Prospective & Low quality & 1979-1982 & Inflatable & 100 & 1 & 1.00 \\
\hline 2 & Furlow et al. [35] & 1987 & Prospective & Low quality & 1985-1987 & Inflatable & 120 & 1 & 0.83 \\
\hline \multirow[t]{2}{*}{3} & $\begin{array}{l}\text { Kabalin and Kessler } \\
\text { [36] }\end{array}$ & 1988 & Prospective & Low quality & 1975-1985 & Scott reoperation & 153 & 4 & 2.61 \\
\hline & & & & & & Scott naive & 264 & 5 & 1.89 \\
\hline 4 & $\begin{array}{l}\text { Cumming and Pryor } \\
\text { [37] }\end{array}$ & 1991 & Prospective & Low quality & 1983-1987 & $\begin{array}{l}\text { Inflatable and mal- } \\
\text { leable }\end{array}$ & 280 & 32 & 11.43 \\
\hline 5 & $\begin{array}{l}\text { Radomski and Her- } \\
\text { schorn [38] }\end{array}$ & 1992 & Prospective & Low quality & 1979-1989 & $\begin{array}{l}\text { Inflatable and semi- } \\
\text { rigid }\end{array}$ & 269 & 6 & 2.23 \\
\hline 6 & Bishop et al. [15] & 1992 & Prospective & Low quality & 1987-1988 & Not sppecified & 90 & 5 & 5.56 \\
\hline 7 & Goldstein et al. [39] & 1993 & Prospective & Low quality & 1989-1991 & Alfa 1-Mentor & 112 & 3 & 2.68 \\
\hline 8 & Choi et al. [40] & 1994 & Retrospective & Low quality & 1983-1993 & Variable & 295 & 3 & 1.02 \\
\hline 9 & Fein et al. [41] & 1994 & Prospective & Low quality & 1988-1991 & GFS II-Mentor & 122 & 5 & 4.10 \\
\hline \multirow[t]{2}{*}{10} & Wilson and Delk [16] & 1995 & Prospective & Low quality & 1986-1993 & Inflatable reoperation & 428 & 43 & 10.05 \\
\hline & & & & & & Inflatable naive & 823 & 24 & 2.92 \\
\hline 11 & $\begin{array}{l}\text { Holloway and Farah } \\
\text { [42] }\end{array}$ & 1997 & Prospective & Low quality & 1989-1994 & Inflatable & 145 & 3 & 2.07 \\
\hline 12 & Anafarta et al. [43] & 1998 & Prospective & Low quality & 1989-1998 & AMS Dynaflex & 120 & 5 & 4.17 \\
\hline 13 & Wilson et al. [10] & 1998 & Prospective & Low quality & 1994-1996 & Inflatable & 389 & 21 & 5.40 \\
\hline 14 & Garber and Marcus[44] & 1998 & Prospective & Low quality & 7 years & Mentor A1 (3piece IPP) & 360 & 6 & 1.67 \\
\hline 15 & $\begin{array}{l}\text { Kabalin and Kessler } \\
\text { [45] }\end{array}$ & 1998 & Prospective & Low quality & 1975-1980 & Scott; Small-carion & 145 & 5 & 3.45 \\
\hline 16 & Montague et al. [46] & 2001 & Retrospective & Low quality & 1986-1999 & $\begin{array}{l}3 \text { piece inflatable; } \\
\text { database }\end{array}$ & 491 & 10 & 2.04 \\
\hline 17 & Cakan et al. [47] & 2003 & Retrospective & Low quality & $1993-2000$ & Malleable 2 piece & 135 & 12 & 8.89 \\
\hline 18 & $\begin{array}{l}\text { Ferguson and Ces- } \\
\text { pedes [48] }\end{array}$ & 2003 & Prospective & Low quality & 1992-1996 & Malleable & 94 & 1 & 1.06 \\
\hline \multirow[t]{2}{*}{19} & Carson [17] & 2004 & Database & Low quality & $2001-2003$ & AMS 700 InhibiZone ${ }^{\mathrm{TM}}$ & 2261 & 15 & 0.66 \\
\hline & & & & & & AMS 700 no coating & 1944 & 32 & 1.65 \\
\hline \multirow[t]{2}{*}{20} & $\begin{array}{l}\text { Wolter and Hellstrom } \\
{[12]}\end{array}$ & 2004 & Database & Low quality & 2002-2003 & Titan coated & 2357 & 25 & 1.06 \\
\hline & & & & & & Alpha 1-no coating & 482 & 10 & 2.07 \\
\hline 21 & Minervini et al. [49] & 2005 & Prospective & Low quality & $1975-2000$ & Malleable_variable & 504 & 40 & 7.94 \\
\hline \multirow[t]{2}{*}{22} & Wilson et al. [23] & 2007 & Database & Low quality & $2001-2004$ & $\begin{array}{l}\text { AMS } 700 \text { InhibiZone }{ }^{\mathrm{TM}} \\
\text { naive }\end{array}$ & 306 & 1 & 0.33 \\
\hline & & & & & & $\begin{array}{l}\text { AMS } 700 \text { InhibiZone }{ }^{\mathrm{TM}} \\
\text { reoperations }\end{array}$ & 161 & 8 & 4.97 \\
\hline 23 & Kim et al. [50] & 2010 & Prospective & Low quality & 1991-2009 & AMS 700 & 397 & 8 & 2.02 \\
\hline 24 & DiBlasio et al. [51] & 2010 & Retrospective & Low quality & 1997-2007 & Inflatable & 79 & 5 & 6.33 \\
\hline \multirow[t]{2}{*}{25} & Carson et al. [19] & 2011 & Database & Low quality & $2001-2008$ & AMS 700 no coating & 3527 & 81 & 2.30 \\
\hline & & & & & & AMS 700 inhibiZone ${ }^{\mathrm{TM}}$ & 34,556 & 408 & 1.18 \\
\hline \multirow[t]{2}{*}{26} & $\begin{array}{l}\text { Mulcahy and Carson } \\
\text { [11] }\end{array}$ & 2011 & Database & Low quality & $2001-2008$ & Inflatable coated & 35,737 & 394 & 1.10 \\
\hline & & & & & & Inflatable no coating & 3268 & 82 & 2.51 \\
\hline 27 & Caire et al. [52] & 2011 & Retrospective & Low quality & $2005-2007$ & Variable; reoperation & 105 & 7 & 6.67 \\
\hline 28 & Dhabuwala et al. [20] & 2011 & Retrospective & Low quality & $2002-2010$ & Titan; AMS InhibiZone ${ }^{\mathrm{TM}}$ & 497 & 10 & 2.01 \\
\hline 29 & Chung et al. [14] & 2013 & Prospective & Low quality & 2006-2010 & $\begin{array}{l}\text { AMS 700; Titan (both } \\
\text { coated) }\end{array}$ & 138 & 3 & 2.17 \\
\hline \multirow[t]{2}{*}{30} & Eid et al. [26] & 2012 & Prospective & Low quality & $8.5 y$ & AMS 700 InhibiZone ${ }^{\mathrm{TM}}$ & 704 & 14 & 1.99 \\
\hline & & & & & & $\begin{array}{l}\text { AMS } 700 \text { Inhibi- } \\
\text { Zone }^{\text {TM }}+\text { "no touch" }\end{array}$ & 1511 & 7 & 0.46 \\
\hline
\end{tabular}


Table 1 (continued)

\begin{tabular}{|c|c|c|c|c|c|c|c|c|c|}
\hline & Study & Year & Design & $\begin{array}{l}\text { Level } \\
\text { of evidence } \\
\text { grade }\end{array}$ & Period & Prosthesis type & Patient $n$ & Infection $n$ & Infectionrate (\%) \\
\hline & & & & & & AMS no coating & 132 & 7 & 5.30 \\
\hline \multirow[t]{2}{*}{31} & Omarbasha et al. [53] & 2012 & Retrospective & Low quality & $2001-2011$ & Variable no coating & 74 & 2 & 2.70 \\
\hline & & & & & & InhibiZone ${ }^{\mathrm{TM}}$ and Titan & 118 & 5 & 4.24 \\
\hline 32 & Henry et al. [54] & 2012 & Prospective & Low quality & $2000-2007$ & Variable reoperation & 214 & 12 & 5.61 \\
\hline 33 & Henry et al. [55] & 2011 & Prospective & Low quality & 2000-2011 & $\begin{array}{l}\text { Variable; salvage } \\
\text { surgeries }\end{array}$ & 148 & 10 & 6.76 \\
\hline 34 & Chung et al. [2] & 2012 & Prospective & Low quality & $1981-2010$ & Variable & 955 & 14 & 1.47 \\
\hline \multirow[t]{2}{*}{35} & Cohen and Eid [56] & 2013 & Prospective & Low quality & 2003-2013 & $\begin{array}{l}\text { Variable coated reop- } \\
\text { eration }\end{array}$ & 120 & 4 & 3.33 \\
\hline & & & & & & $\begin{array}{l}\text { Reoperation and "no } \\
\text { touch" }\end{array}$ & 283 & 1 & 0.35 \\
\hline 36 & Pozza et al. [57] & 2015 & Prospective & Low quality & 1984-2013 & Variable & 500 & 15 & 3.00 \\
\hline 37 & Mohamed et al. [29] & 2016 & Retrospective & Low quality & 2008-2015 & Malleable & 128 & 7 & 5.47 \\
\hline 38 & Chiang et al. [7] & 2016 & Prospective & Low quality & 2004-2008 & Variable & 91 & 6 & 6.59 \\
\hline 39 & Antonini et al. [58] & 2016 & Prospective & Low quality & 2011-2013 & $\begin{array}{l}\text { AMS } 700 \text { e Titan both } \\
\text { coated }\end{array}$ & 180 & 5 & 2.78 \\
\hline 40 & Katz and Love [59] & 2017 & Prospective & Low quality & 2012-2015 & $\begin{array}{l}\text { Inflatable coated +"no } \\
\text { touch" }\end{array}$ & 150 & 1 & 0.67 \\
\hline 41 & Sevinc et al. [60] & 2017 & Prospective & Low quality & 1998-2012 & $\begin{array}{l}\text { Malleable and inflat- } \\
\text { able }\end{array}$ & 181 & 4 & 2.21 \\
\hline
\end{tabular}

Studies
Carson et al (37) 1983
Cumming and Pryor (41) 1991
Radomski and Hellstrom (59) 1991
Bishop et al (15) 1992
Wilson and Delk (16) 1995
Wilson and Delk - revisions (16) 1995
Anafarta et al (33) 1998
Wilson et al (16) 1998
Garber and Marcus (46) 1998
Montague et al (56) 2001
Minervini et al (55) 2005
Wilson et al (23) 2007
DiBlasio et al (42) 2010
Kim et al (54) 2010
Mulcahy et al - no coating (11) 2011
Mulcahy et al - inhibizone (11) 2011
Eid et al - inhibizone no touch (26) 2012
Mohamed et al (28) 2016
Antonini et al (34) 2016
Chiang et al (7) 2016
Sevinc et al (60) 2017
eid et al - inhibizone (26) 2012
eid et al - no coating (26) 2012
Chung et al (2) 2013
Overall (I^2=3248 \%, P=0.064)

Overall ( $\left(\wedge^{\wedge} 2=3248 \%, P=0.064\right)$

\begin{tabular}{|c|c|c|c|c|}
\hline \multicolumn{3}{|c|}{ Estimate (95z C.I.) } & \multirow{2}{*}{$\begin{array}{c}\text { Ev/Trt } \\
1 / 25\end{array}$} & \multirow{2}{*}{$\begin{array}{c}\text { Ev/Ctrl } \\
0 / 75\end{array}$} \\
\hline .245 & $(0.365$ & 234.3841 & & \\
\hline 2.391 & $(0.942$ & $6.068)$ & $7 / 33$ & $25 / 247$ \\
\hline 0.756 & $(0.087$ & 6.6081 & $1 / 56$ & $5 / 213$ \\
\hline 3.400 & (1.249, & 438.3631 & $5 / 32$ & $0 / 58$ \\
\hline 0.333 & 10.119 & 0.9331 & $4 / 125$ & $63 / 698$ \\
\hline 2.368 & (1.091, & 5.1411 & $10 / 55$ & $32 / 373$ \\
\hline 1.636 & $(0.263$ & $10.162)$ & $3 / 58$ & $2 / 62$ \\
\hline 2.308 & 10.952 & 5.5971 & $10 / 114$ & $11 / 275$ \\
\hline 3.057 & $(0.553$ & $16.915)$ & $4 / 144$ & $2 / 216$ \\
\hline 1.110 & $(0.283$, & 4.3551 & $3 / 137$ & $7 / 354$ \\
\hline 1.309 & 10.636 & 2.6951 & $12 / 122$ & $25 / 325$ \\
\hline 8.127 & $(0.328$ & 201.4971 & $1 / 83$ & $0 / 223$ \\
\hline 3.590 & $(0.383$, & 33.6631 & $4 / 43$ & $1 / 36$ \\
\hline 0.835 & $(0.166$ & $4.199)$ & $2 / 113$ & $6 / 284$ \\
\hline 2.251 & $(1.400$, & 3.6191 & $26 / 624$ & $55 / 2903$ \\
\hline 1.314 & $(1.037$ & $1.664)$ & $89 / 6071$ & $319 / 28485$ \\
\hline 0.528 & $(0.102$, & 2.7321 & $2 / 650$ & $5 / 861$ \\
\hline 1.959 & $(0.420$ & 9.1421 & $4 / 53$ & $3 / 75$ \\
\hline 4.750 & $(0.520$ & $43.360)$ & $4 / 84$ & $1 / 96$ \\
\hline 5.200 & $(0.861$ & 31.4211 & $4 / 19$ & $2 / 41$ \\
\hline 0.404 & 10.041 & $3.961)$ & $1 / 81$ & $3 / 100$ \\
\hline 0.440 & $(0.122$ & 1.5921 & $3 / 267$ & $11 / 437$ \\
\hline 0.600 & 10.112, & 3.2141 & $2 / 52$ & $5 / 80$ \\
\hline 1.914 & $(0.454$, & $8.072)$ & $3 / 229$ & $5 / 726$ \\
\hline & 1.146, & $2.037)$ & $205 / 9270$ & $588 / 37243$ \\
\hline
\end{tabular}

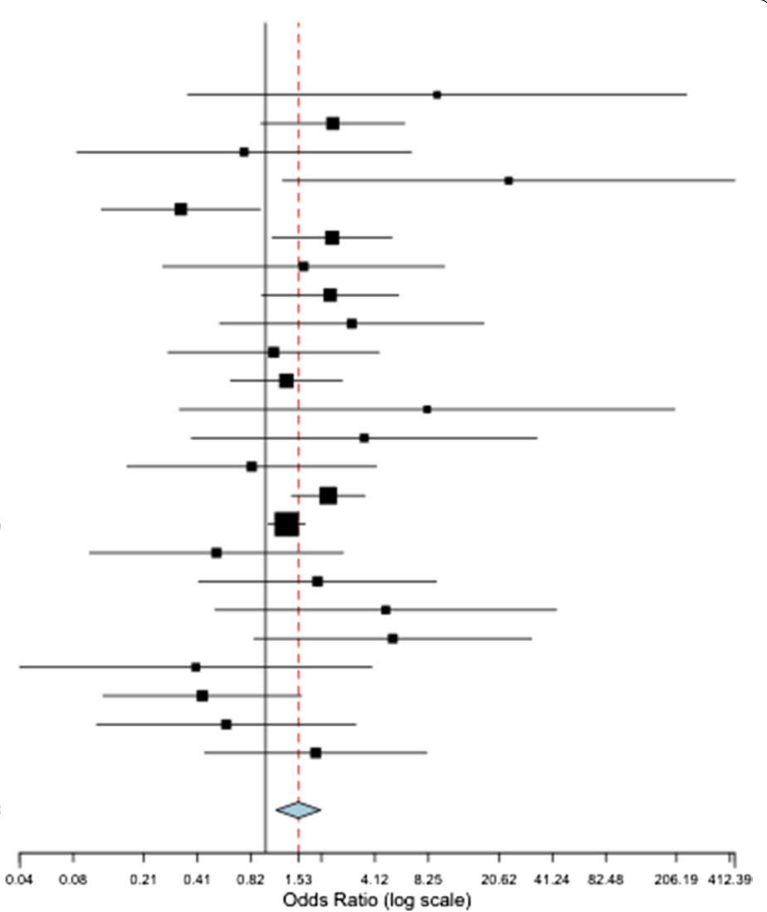

Fig. 2 Forest plot diagram showing articles included in meta-analysis. The overall result shows that diabetic patients have more infections of penile prosthesis than non-diabetics, with an odds ratio of $1.53(95 \% \mathrm{Cl} 1.15-2.04 ; p=0.004)$

implants was $1.06 \%(25 / 2357)$, while in non-coated prosthesis it was $2.07 \%(10 / 482)(p 0.033)[12]$.
In 2011, Carson et al. published an extensive manufacturer's database review, including more than 39 
thousand implants, with $90 \%$ of them with InhibiZone ${ }^{\mathrm{TM}}$; implanted between 2001 and 2008 and followed up to 7.7 years. They found that the revision rate for all causes (not only due to infection) was significantly lower on coated implants $(6.7 \%$ vs. $12.5 \%$, log-rank $p=0.002)$ [19]. Dhabuwala et al. compared the Titan immersed in rifampicin $10 \mathrm{mg} / \mathrm{ml}$ and gentamicin $1 \mathrm{mg} / \mathrm{ml}$ or vancomycin and gentamicin to AMS with InhibiZone ${ }^{\mathrm{TM}}$. There was no difference in infection rates between InhibiZone ${ }^{\mathrm{TM}}$ $(1 / 77)$ and Titan with rifampicin and gentamicin $(0 / 81)$. However, the vancomicyn + gentamicin group had $4.4 \%$ of infection (8/181), which was significantly higher than the other two groups $(p<0.05)$ [20]. Coated implants also had better results than regular ones regarding infection when used in reoperations [21-23].

The concept of "center of excellence" is widely used for heart and oncologic surgeries, based on the evidence that surgeons with a high volume of a specific surgery trend to have superior outcomes. In 2009, Henry et al. introduced this concept to the urological field, comparing the results of penile prosthesis implants of a high volume urologist with ten general urologists. The single urologist had more than 50 cases per year, had shorter operative time (34 min versus $94 \mathrm{~min}, p<0.0001$ ), and eight-fold fewer reoperations $(p$ 0.028). The concept was adopted and included as a recommended strategy to reduce infection $[24,25]$.

The most recent strategy was a technical improvement, presented by Eid in 2011, called the "no-touch" technique. It includes an antibiotic coated drape over the skin to reduce contact of hands and materials with the patient's skin [26]. In 2012, the same authors achieved an infection incidence of $0.4 \%$ using coated prosthesis and the "no-touch" technique [26].

\section{Discussion}

This review presents essential information from a wide variety of available articles in ten databases and brings contemporary data about penile prosthesis infections. It summarizes device and technique improvements that contributed to reduction of infection and reoperations. Although penile prosthesis infection has decreased over the last decades, it is still a feared complication once it leads to reoperation, loss of function, and increases costs $[8,27]$.

For the first time, we present a meta-analysis about diabetes mellitus role in penile prosthesis infection, which brings light to a long controversy. The meta-analysis suggests that DM is related to a higher risk of penile prosthesis infection, with an odds ratio of 1.53. There is a considerable heterogeneity, which comes from the different studies' designs, and significant disparity in the number of subjects. The results at both sides of the forest plot show the controversy in the literature.

While older studies, from the 1990s, started to suggest the higher infection rates in diabetic patients, subsequent studies did not confirm it [28]. However, it is crucial to notice that most of the studies were not designed to evaluate DM properly, and most of them lack information about diabetes treatments and glucose control. For example, Mohamed et al. [29] reported that all patients in his study had glycosylated hemoglobin inferior to $7.0 \%$. Thus, one may consider the contemporary practice to achieve good glycemic control before elective surgeries, and the lack of information about glycemic control on the databases. That may limit the evaluation of the glycosylated hemoglobin (Hb1Ac) role in most studies and contribute to the controversy regarding diabetes mellitus relation with infection.

In this scenario, it is essential to look at a prospective study designed to predict the importance of Hb1Ac levels at penile prosthesis infection. Habous et al. [30] recently analyzed 902 patients, who received different types of penile prosthesis, and found that Hb1Ac was significantly related to a higher incidence of infection. They had 80 implants with infection, which means an infection rate of $8.9 \%$. The mean Hb1Ac in patients with infection was $9.5 \%$, and it was significantly higher than in patients with no infection, with a mean Hb1Ac of $7.8 \%(p<0.001)$. They constructed a ROC curve and proposed the Hb1Ac level of $8.5 \%$ as the threshold to predict infection with $80 \%$ sensitivity and $65 \%$ specificity.

Li et al. [6] also in 2018 reported diabetes mellitus, $\mathrm{HIV}$, and Charles Comorbidity Index as factors associated with prosthesis removal. On the other hand, a recent retrospective study performed by Canguven et al. [31] included 300 patients and had only 2 cases of prosthesis infection, and both of them on non-diabetic patients. A superficial comparison could easily trick with the conflicting results, but one needs caution to interpret the studies' designs. A retrospective cohort may present biases, mainly due to the lack of information provided by patient charts or data loss, which invariably interfere with the results. The recent studies focused on penile prosthesis complications confirm our meta-analysis finding.

Our review is limited by the quality of the available evidence, the lack of controls, and studies based on the manufacturer's database and FDA reports, which may have standardization and selection biases. However, it is crucial to consider the low incidence of infection, which requires a very high number of patients to show a decrease of incidence. Considering a baseline infection rate of $3 \%$, it is estimated that a prospective study would require about 3 thousand patients to show a 50\% reduction on infection rate or 34 thousand patients to 
show a $25 \%$ reduction [32]. It is also difficult to propose a trial to compare coated and uncoated implants when the available evidence suggest the superiority of the coated ones, which could bring ethical issues to the trial [33].

This is the most extensive review about penile prosthesis infection to our knowledge, including references from 10 databases, which brings information from the current scenario of penile prosthesis infection and gathers enough data to perform the first meta-analysis about the role of DM in penile prosthesis infection. The results encourage further studies focused on diabetic patients, which will be interesting to evaluate glycosylated hemoglobin levels, treatments in use, and the time elapsed from DM diagnosis to surgery.

\section{Conclusions}

Penile prosthesis infection decreased in the last decades due to several improvements in materials and techniques. It remains a significant complication, and the meta-analysis indicates that diabetes mellitus is related to a higher risk of penile prosthesis infection.

\section{Acknowledgements \\ Special thanks to Ana Paula de Morais e Oliveira and all the staff from the Library of the Faculty of Medical Sciences_-University of Campinas for sup- porting data acquisition.}

\section{Authors' contributions}

LG and LP did the project conception and development. CC and BV have collected and analyzed data. LG and CR had supervised the data management and analysis. LG drafted the manuscript, while CC, BV and CR edited and revised it. AF gave intelectual contributions and critical revision of the manuscript. All authors read and approved the final manuscript.

\section{Funding}

The research had no financial support.

\section{Availability of data and materials}

All data is fully provided. The subject of research was previous studies since it is a systematic review. All the studies are listed in a table and the full references are provided.

\section{Ethics approval and consent to participate}

The study was assessed by institutional board review which has approved the study with no informed consent due to its design. It is a systematic review of previous studies, thus it doesn't report or involve animal or human data. It followed the PRISMA recomendations, and it is registered at PROSPERO (York University) with number: 42019117734 . There was no individual participants. As a systematic review, data was obtained from other studies with no patient identification.

\section{Informed consent}

Not applicable.

\section{Consent for publication}

Not applicable. The manuscript is a systematic review and therefore it does not contain individual data.

\section{Competing interests}

The Authors declare that they have no competing interests. All authors agree with BMC Urology editorial policies.
Received: 15 June 2019 Accepted: 25 September 2020

Published online: 10 March 2021

\section{References}

1. Scott FB, Bradley WE, Timm GW. Management of erectile impotence. Use of implantable inflatable prosthesis. Urology. 1973;2(1):80-2.

2. Chung E, Van CT, Wilson I, Cartmill RA. Penile prosthesis implantation for the treatment for male erectile dysfunction: clinical outcomes and lessons learnt after 955 procedures. World J Urol. 2013;31(3):591-5.

3. Rajpurkar A, Dhabuwala CB. Comparison of satisfaction rates and erectile function in patients treated with sildenafil, intracavernous prostaglandin E1 and penile implant surgery for erectile dysfunction in urology practice. J Urol. 2003;170(1):159-63.

4. Bennett N, Huang IS. Inflatable penile prosthesis in the radical prostatectomy patient: a review. F1000Res. 2018;7:770.

5. Natali A, Olianas R, Fisch M. Penile implantation in Europe: successes and complications with 253 implants in Italy and Germany. J Sex Med. 2008:5(6):1503-12.

6. Li K, Brandes ER, Chang SL, Leow JJ, Chung BI, Wang Y, et al. Trends in penile prosthesis implantation and analysis of predictive factors for removal. World J Urol. 2018;37:639-46.

7. Chiang HS, Liao CH, Chang ML. Benefits of antibiotic-impregnated inflatable penile prosthesis $\left(\right.$ InhibiZone $\left.{ }^{\circledR}\right)$ in patients at high risk of infection in Taiwan. Urol Sci. 2016;27(3):144-7.

8. Carson C. Antibiotic impregnation of inflatable penile prostheses: effect on perioperative infection. Expert Rev Med Devices. 2004; 1 (2):165-7.

9. Angulo J, Gonzalez-Corrochano R, Cuevas P, Fernandez A, La Fuente JM, Rolo F, et al. Diabetes exacerbates the functional deficiency of NO/cGMP pathway associated with erectile dysfunction in human corpus cavernosum and penile arteries. J Sex Med. 2010;7(2 Pt 1):758-68.

10. Wilson SK, Carson CC, Cleves MA, Delk 2nd JR. Quantifying risk of penile prosthesis infection with elevated glycosylated hemoglobin. J Urol. 1998;159(5):1537-9 (discussion 9-40).

11. Mulcahy JJ, Carson CC 3rd. Long-term infection rates in diabetic patients implanted with antibiotic-impregnated versus nonimpregnated inflatable penile prostheses: 7-year outcomes. Eur Urol. 2011;60(1):167-72.

12. Wolter CE, Hellstrom WJ. The hydrophilic-coated inflatable penile prosthesis: 1-year experience. J Sex Med. 2004;1 (2):221-4

13. Atkins D, Eccles M, Flottorp S, Guyatt GH, Henry D, Hill S, et al. Systems for grading the quality of evidence and the strength of recommendations I: critical appraisal of existing approaches The GRADE Working Group. BMC Health Serv Res. 2004:4(1):38.

14. Chung E, Solomon M, Deyoung L, Brock GB. Comparison between AMS $700^{\mathrm{TM}} \mathrm{CX}$ and Coloplast ${ }^{\mathrm{TM}}$ titan inflatable penile prosthesis for Peyronie's disease treatment and remodeling: clinical outcomes and patient satisfaction. J Sex Med. 2013;10(11):2855-60.

15. Bishop JR, Moul JW, Sihelnik SA, Peppas DS, Gormley TS, McLeod DG. Use of glycosylated hemoglobin to identify diabetics at high risk for penile periprosthetic infections. J Urol. 1992;147(2):386-8.

16. Wilson SK, Delk JR 2nd. Inflatable penile implant infection: predisposing factors and treatment suggestions. J Urol. 1995;153(3 Pt 1):659-61.

17. Carson CC 3rd. Efficacy of antibiotic impregnation of inflatable penile prostheses in decreasing infection in original implants. J Urol. 2004;171(4):1611-4.

18. Henry GD. Historical review of penile prosthesis design and surgical techniques: part 1 of a three-part review series on penile prosthetic surgery. J Sex Med. 2009;6(3):675-81.

19. Carson CC 3rd, Mulcahy JJ, Harsch MR. Long-term infection outcomes after original antibiotic impregnated inflatable penile prosthesis implants: up to 7.7 years of followup. J Urol. 2011;185(2):614-8.

20. Dhabuwala C, Sheth S, Zamzow B. Infection rates of rifampin/gentamicincoated Titan Coloplast penile implants, Comparison with Inhibizoneimpregnated AMS penile implants. J Sex Med. 2011;8(1):315-20.

21. Brant MD, Ludlow JK, Mulcahy JJ. The prosthesis salvage operation: immediate replacement of the infected penile prosthesis. J Urol. 1996;155(1):155-7.

22. Mulcahy J. Long-term experience with salvage of infected penile implants. J Urol. 2000;163(2):481-2. 
23. Wilson SK, Zumbe J, Henry GD, Salem EA, Delk JR, Cleves MA. Infection reduction using antibiotic-coated inflatable penile prosthesis. Urology. 2007;70(2):337-40.

24. Henry GD, Kansal NS, Callaway M, Grigsby T, Henderson J, Noble J, et al. Centers of excellence concept and penile prostheses: an outcome analysis. J Urol. 2009;181(3):1264-8.

25. Levine LA, Becher EF, Bella AJ, Brant WO, Kohler TS, Martinez-Salamanca II, et al. Penile prosthesis surgery: current recommendations from the international consultation on sexual medicine. J Sex Med. 2016:13(4):489-518.

26. Eid JF, Wilson SK, Cleves M, Salem EA. Coated implants and "no touch" surgical technique decreases risk of infection in inflatable penile prosthesis implantation to 0.46\%. Urology. 2012;79(6):1310-5.

27. Mulcahy JJ. Penile prosthesis infection: progress in prevention and treatment. Curr Urol Rep. 2010;11(6):400-4.

28. Christodoulidou M, Pearce I. Infection of penile prostheses in patients with diabetes mellitus. Surg Infect (Larchmt). 2016;17(1):2-8.

29. Mohamed ER, Hammady AR, Eldahshoury MZ, Elsharkawi AM, Riad AM, Elmogazy HM, et al. Surgical outcomes and complications of Tube(R) (Promedon) malleable penile prostheses in diabetic versus non-diabetic patients with erectile dysfunction. Arab J Urol. 2016;14(4):305-11.

30. Habous M, Tal R, Tealab A, Soliman T, Nassar M, Mekawi Z, et al. Defining a glycated haemoglobin ( $\mathrm{HbA} 1 \mathrm{c})$ level that predicts increased risk of penile implant infection. BJU Int. 2018;121(2):293-300.

31. Canguven O, Talib R, El Ansari W, Khalafalla K, Al Ansari A. Is Hba1c level of diabetic patients associated with penile prosthesis implantation infections? Aging Male. 2019;22(1):28-33. https://doi.org/10.1080/13685 538.2018.1448059.

32. Darouiche RO. Antimicrobial approaches for preventing infections associated with surgical implants. Clin Infect Dis. 2003;36(10):1284-9.

33. Al Mohajer M, Darouiche RO. Infections associated with inflatable penile prostheses. Sex Med Rev. 2014;2(3-4):134-40.

34. Carson CC. Inflatable penile prosthesis: experience with 100 patients. South Med J. 1983;76(9):1139-41.

35. Furlow WL, Goldwasser B, Gundian JC. Implantation of model AMS 700 penile prosthesis: long-term results. J Urol. 1988;139(4):741-2.

36. Kabalin JN, Kessler R. Five-year followup of the Scott inflatable penile prosthesis and comparison with semirigid penile prosthesis. J Urol. 1988a;140(6):1428-30.

37. Cumming J, Pryor JP. Treatment of organic impotence. Br J Urol. 1991;67(6):640-3.

38. Radomski SB, Herschorn S. Risk factors associated with penile prosthesis infection. J Urol. 1992:147(2):383-5.

39. Goldstein I, Bertero EB, Kaufman JM, Witten FR, Hubbard JG, Fitch WP, et al. Early experience with the first pre-connected 3-piece inflatable penile prosthesis: the Mentor Alpha-1. J Urol. 1993;150(6):1814-8.

40. Choi HK, Cho IR, Xin ZC. Ten years of experience with various penile prosthesis in Korean. Yonsei Med J. 1994;35(2):209-17.

41. Fein RL. GFS Mark II inflatable penile prosthesis: four-year clinical study. Urology. 1994;43(2):209-13.

42. Holloway FB, Farah RN. Intermediate term assessment of the reliability, function and patient satisfaction with the AMS700 Ultrex penile prosthesis. J Urol. 1997;157(5):1687-91.

43. Anafarta K, Yaman O, Aydos K. Clinical experience with Dynaflex penile prostheses in 120 patients. Urology. 1998;52(6):1098-100.

44. Garber BB, Marcus SM. Does surgical approach affect the incidence of inflatable penile prosthesis infection? Urology. 1998;52(2):291-3.
45. Kabalin JN, Kessler R. Infectious complications of penile prosthesis surgery. J Urol. 1988b;139(5):953-5.

46. Montague DK, Angermeier KW, Lakin MM. Penile prosthesis infections. Int J Impot Res. 2001;13(6):326-8.

47. Cakan M, Demirel F, Karabacak O, Yalcinkaya F, Altug U. Risk factors for penile prosthetic infection. Int Urol Nephrol. 2003;35(2):209-13.

48. Ferguson $\mathrm{KH}$, Cespedes RD. Prospective long-term results and qualityof-life assessment after Dura-II penile prosthesis placement. Urology. 2003:61(2):437-41.

49. Minervini A, Ralph DJ, Pryor JP. Outcome of penile prosthesis implantation for treating erectile dysfunction: experience with 504 procedures. BJU Int. 2006;97(1):129-33.

50. Kim DS, Yang KM, Chung HJ, Choi HM, Choi YD, Choi HK. AMS 700CX/ CXM inflatable penile prosthesis has high mechanical reliability at longterm follow-up. J Sex Med. 2010;7(7):2602-7.

51. DiBlasio CJ, Kurta JM, Botta S, Malcolm JB, Wan JY, Derweesh IH, et al. Peyronie's disease compromises the durability and component-malfunction rates in patients implanted with an inflatable penile prosthesis. BJU Int. 2010;106(5):691-4.

52. Caire A, Boonjindasup A, Richardson B, Hellstrom W. Does the need for a replacement inflatable penile prosthesis lead to decreased patient satisfaction? J Urol. 2011;185(4):e369.

53. Omarbasha B, Basso AC, Howland L, Wilson S. Penile implant infections experienced in a community practice during the ERA of the coated implant. J Sex Med. 2012;9:7-8.

54. Henry G, Wilson SK, Donatucci C, Delk J, Lentz A, McNamara E, et al. Single component exchange during penile prosthesis revision appears to have higher infection rates and lower overall device survival rates than complete component replacement: a multicenter analysis. J Urol. 2012;187(4):e752-3

55. Henry G, Carson C, Delk J, McKim S, McNamara E, Cleves M, et al. Positive culture growths from infection retardant-coated penile prostheses at the time of revision/savlage surgery: a multicenter study. J Urol. 2011;185(4):e723

56. Cohen SD, Eid JF. The "no touch" technique decreases the risk of infection after removal and replacement of malfunctioned penile prosthesis to 0.35\%. J Urol. 2013;189(4):e685-6.

57. Pozza D, Pozza M, Musy M, Pozza C. 500 penile prostheses implanted by a surgeon in Italy in the last 30 years. Arch Ital Urol Androl. 2015;87(3):216-21.

58. Antonini G, Busetto GM, De Berardinis E, Giovannone R, Vicini P, Del Giudice $F$, et al. Minimally invasive infrapubic inflatable penile prosthesis implant for erectile dysfunction: evaluation of efficacy, satisfaction profile and complications. Int J Impot Res. 2016;28(1):4-8.

59. Katz DJ, Love C. The minimally invasive no touch (MINT) penile implant, the first 150 consecutive cases. J Sex Med. 2017;14(1):S18-9.

60. Sevinc C, Ozkaptan O, Balaban M, Yucetas U, Karadeniz T. Outcome of penile prosthesis implantation: are malleable prostheses an appropriate treatment option in patients with erectile dysfunction caused by prior radical surgery? Asian J Androl. 2017;19(4):477-81.

\section{Publisher's Note}

Springer Nature remains neutral with regard to jurisdictional claims in published maps and institutional affiliations. 